\title{
SIMPLE WEIGHTED AVERAGE AS AN ALTERNATIVE METHOD IN AGGREGATING STUDENTS' ACADEMIC ACHIEVEMENTS
}

\author{
Maznah Mat Kasim ${ }^{1}$ \\ School of Quantitative Sciences \\ Universiti Utara Malaysia
}

Siti Rohana Goh Abdullah

Institutes of Engineering Mathematics

Universiti Malaysia Perlis

${ }^{1}$ Corresponding author: maznah@uum.edu.my

\begin{abstract}
Purpose - It is a normal practice that students' overall scores are computed by simple average (SA) method which considers all academic subjects as having the same weights or same degree of importance. This paper highlights the application of simple weighted average (SWA) as an alternative method in aggregating students' academic achievements. The weights of the academic subjects must be determined prior to the use of SWA.

Methodology - In a case study, a group of five teachers from one primary school was asked to rate five main subjects taught in primary schools according to their importance. These five teachers have taught the five subjects for more than six years. The obtained weights values were used to re-compute 2011 mid-semester final examination scores of 33 year-six pupils at the selected primary school.

Findings - The teachers decided to give different weight to three subjects, but same weights to two subjects. Furthermore, the SWA scores give different ranking to the pupils as compared to the SA scores. Another sentence or two needed here to explain the findings.
\end{abstract}


Significance - It is argued that the use of the SWA method is more suitable than the simple average method in finding the overall scores of students' achievements. The SWA method considers the subjects to have different degrees of importance, as they do in the actual educational context.

Keywords: academic subject, academic achievement, student assessments, simple weighted average

\section{INTRODUCTION}

For the past few years, schools in Malaysia have been introduced applying information systems for administrative and education management. The systems include the Student Information System, Education Management Information System (EMIS), School Examination Analysis System (SAPS), and Integrated Students Information System (ISIS) (Mohd Faisal Imran, 2007). The data stored in these systems can also be used and accessed by other parties, especially the District Education Office and State Department of Education (JPN).

The ISIS, which was developed to collect, store, analyze data of internal examinations and evaluate students' performance, is the most well-known and user-friendly system. Due to its versatility, it has been widely used by schools all over the country. The ISIS allows teachers to evaluate students' academic achievement, based on the final aggregated scores. Aggregation refers to the process of combining several numerical performance scores of each student by a certain procedure to produce the final single score. The aggregation method provided in the ISIS is a Simple Average (SA) method and the final score for every student is obtained by summing all his/ her scores of different subjects and dividing the sum by the number of subjects.

In the United States, the same method is used in calculating the American College Testing (ACT) test score, which is used as a partial evaluation in the college admission process (www.actstudent.org, 2012). The ACT test is a standardized test which consists of four subjects: English, Mathematics, Reading, and Science Reasoning. These four subjects are scored individually on a scale between one 
and 36. The overall scores of students are provided as composite scores which are calculated as the simple average of the four tests scores. In another context as reported by Yao (2010), the SA method is also adopted in TerraNova ${ }^{\mathrm{TM}}$, a product of CTB/McGraw-Hill, which measures five main content areas or subjects: Mathematics, Reading, Language, Science and Social Studies.

The use of SA in finding composite scores of students implies that all subjects or tests are independent of each other and carry equal importance or equal weight, which is naturally and logically not true all the time in real world classrooms (Tan \& Chen, 2010; Muhamad Ayub, 2009). Besides that, the use of SA ignores the fact that different subjects have different score points, that scores from those subjects are related, and that, at different score points, the relationship between overall score and subject score may be different (Yao, 2010). As these composite scores are used in ranking, grouping or selecting the students for their future learning processes, a different average method should be considered as an alternative or as an additional method in calculating these overall scores.

A promising average method is known as Simple Weighted Average (SWA) in which the subjects are assumed to have different level of importance or weights. The SWA method can be utilized once the weights, which usually represent the degree of importance of the subjects, are available (Choo, Schooner, \& Wedley, 1999). This raises another issue. Do the subjects really carry different weights based on their value and, if so, what are the ways to determine their relative importance? In actual fact, parents, teachers and students assign academic subjects different levels of importance. These different levels can be measured approximately by the amount of time the students spend studying, or by how much money the parents spend for extra tuition sessions or for extra reference books. Besides that, the different relative importance of the subjects can be measured by the level of difficulty of these subjects. Assuming all these differences, it can be concluded that the level of importance of these academic subjects is varied and the variation is very subjective, depending upon the evaluators and the context in which the evaluation is made. Moreover, the existence of subjectivity in this type of evaluation leads to the exclusion of academic subjects level of importance in aggregating student's academic scores. 
A survey, conducted by Focus Taiwan News Channel release on 19 June 2012 shows that parents polled placed a higher premium on language subjects and math than on natural science (Wei \& Hsio, 2012). Another study conducted by a chemical company, Baden Aniline and Soda Factory (BASF) of Taiwan, found similar results. When parents were asked about the subjects their fifth and sixthgraders children study at school, they said that the most important subjects are Chinese, English, Math, Natural Science, and Social Education in descending order.

In terms of the use of different methods in finding students' composite scores, there are very few studies which discuss the matter. One study conducted by Kane and Case (2004) noted that combining measures of distinct competencies into single variable is desirable in many achievement testing contexts. However, their work focused on the issue of combining scores in one subject which resulted from different types of testing. Kolen, Wang and Lee (2012) also agreed on the use of composite scores to represent the overall scores of students, but, since measurements are subject to errors, they presented the procedure for estimating conditional standard errors of measurement and reliability for composite scores. A study by Yao (2010) reports on the use of four methods: the unidimensional Item Response Theory (IRT) model, the higherorder IRT model, the multidimensional IRT model and the bifactor general model to estimate the overall ability and subject ability of the students.

This study is conducted in the spirit of highlighting the use of composite single scores to represent overall achievement scores of students as this type of score is easier from the perspective of decision makers. However, this paper focuses on a different type of composite method which considers the relative importance of the subjects taught in one primary school in Malaysia. It is worth noting that all year-six pupils in Malaysia would sit for a national examination, the Ujian Penilaian Sekolah Rendah (UPSR) or Primary School Evaluation Test (PSET) at the end of the year. The test consists of five subjects: Mathematics, Science Malay Language Comprehension, Malay Written Malay Language and English Language, and the scores ranged from 0 to 100. All primary schools conduct the same tests, since the results of UPSR serve as the basis 
for entrance to boarding schools in Malaysia. The results from the school's level tests are usually used by the teachers to monitor the preparedness of their pupils for the UPSR.

So, for the purpose of this research, five teachers, who taught the five test subjects and had taught year-six children for more than six years, were asked to judge on the relative importance of these five mains subjects. Then, the average weights of these five subjects were calculated. The SWA method was used to re-compute the composite scores for 2011 mid- semester examination of 33 year six pupils of the selected school. In addition, the ranking of the students was determined by their final single composite score. This new ranking was compared with the ranking based on the SA. Obviously, the two rankings were different and carried different interpretations. SA rankings were based on scores which treated all subjects as having equal degree of importance, whereas SWA scores resulted from giving different importance to the subjects.

\section{WEIGHTING METHODS}

There are many methods available that can determine the relative importance of criteria in solving multi-criteria problems. In this study the criteria are the academic subjects, while the students are the units to be evaluated on these subjects. In general, the weighting methods can be classified into two main approaches, subjective and objective approaches (Ma, Fan \& Huang, 1999). The objective approach depends heavily on the quantitative intrinsic information contained in each criterion, where the information is manipulated mathematically to generate new information, such as the standard deviation, entropy, correlation, and variation coefficient (Diakoulaki, Mavrotas, \& Papayannakis, 1995; Hwang \& Yoon, 1981; Maznah Mat Kasim, 2008). This implies that the objective method can be used only if the quantitative information in every criterion is already available. Based on these measures, the weights of the criteria can be determined.

Another approach, which is called subjective approach, requires that the evaluator(s) make a judgment on the importance of the criteria. For example, by using the Analytical Hierarchy Process 
(AHP), method, the evaluator(s) is asked to compare the relative importance of the criteria by examining them in pairs (Saaty 1990). A less complex method is based on rank. Here the evaluator(s) has to rank the criteria according to their importance, and the weights of the criteria can be calculated based on the rankings (Barron \& Barrett, 1996). Another possible method is by direct rating method where the evaluator(s) will give values between zero and one to every criterion; the criterion which is judged as more important will get more value, but the sum of these values must be one. This paper discusses the utilization of this direct rating method in the selected case study.

\section{AGGREGATION METHODS}

As previously mentioned, an aggregation phase consists of a function, composed of the performance scores of each analyzed unit, to produce a single global score (Hazura, Abdul Azim, Mohd Hasan \& Ramlan, 2007; Marichal, 1999). In the context of this paper, the analyzed units are the students, the evaluation criteria are the academic subjects, and the decision makers are the people who are responsible to make educational determinations based on the students' overall achievements. This final single score will become the basis for decision makers in selecting, ranking or sorting the alternatives.

\section{Simple Average Method (SA)}

SA is basically the normal average method where the final score of a student is obtained by dividing the total scores by the number of subjects. For example, suppose the following values: 50, 67, 89, 43, and 58 are scores of a student in the five tested subjects. If the SA method is used, then the final score of that student is

$$
\frac{50+67+89+83+58}{5}=69.4
$$

In general, final score for student $I$ according to the SA method can be written as Final score for student $\mathrm{i}=\frac{M_{i}+S_{i}+M C_{i}+M W_{i}+E_{i}}{5}$ where $\mathrm{M}$ represents mathematics; $\mathrm{S}$, science; MC Malay comprehension; 
MW, written Malay and E, English. In equation (2), $\mathrm{M}_{\mathrm{i}}, \mathrm{S}_{\mathrm{i}}, \mathrm{MC}_{\mathrm{i}}$, $\mathrm{MW}_{\mathrm{i}}$ and $\mathrm{E}_{\mathrm{i}}$ represent scores of student $i$ for the respected subjects.

\section{Simple Weighted Average (SWA) Method}

In SWA, equation (1) can be written equivalently as

$$
\frac{1}{5}(50)+\frac{1}{5}(67)+\frac{1}{5}(89)+\frac{1}{5}(83)+\frac{1}{5}(58)=69.4
$$

This means that $\mathrm{SA}$ is the same as the simple equally weighted average method. Furthermore, in equation (3), $\frac{1}{5}$ is multiplied to every score, and the products are summed to become 69.4. This value can be interpreted as the weight, or the relative importance, of each subject. This $\frac{1}{5}$ value means the total value of the importance is normally 1 (or $100 \%$ ). Since there are five subjects, 1 is divided equally by 5 to become $\frac{1}{5}(20 \%)$. This implies that all subjects have equal relative importance, which, previous research has shown, is not true in the educational context.

In using SWA, the weights or the relative importance of the subjects should be different. Let $w_{M}, w_{S}, w_{M C}, w_{M W} w_{E}$ be the weights for $\mathbf{M}$, $\mathrm{S}, \mathrm{MC}, \mathrm{MW}$, and $\mathrm{E}$ respectively. Generally, final score for student $i$ is as follows.

$$
\begin{aligned}
& \text { Final score for student } \mathrm{i}=w_{M} M_{i}+w_{S} S_{i}+w_{M C} M C_{i}+ \\
& w_{M W} M W_{i}+w_{E} E_{i} .
\end{aligned}
$$

In this study, the relative importance of the five core subjects which are taught in primary schools were determined subjectively by teachers, each of whom taught one of the tested subjects who have taught the related subjects to the year-six students in one primary school in the State of Perlis, Malaysia. They were asked to rate the five subjects according to the following rating scale as potrayed in Table 1 (Wagholikar, 2007; Wagholikar \& Deer, 2007, and Wagholikar \& Jo, 2008).

\section{RESULTS AND DISCUSSION}

A set of 33 year-six students' exam scores was used as the basis of calculation. All scores were standardized between zero and 100. The summary of raw scores is illustrated in Table 2. 
Table 1

Linguistic Scales for the Importance Weight

\begin{tabular}{ccc}
\hline & Extremely & 0.0 \\
The subject is less & Highly & 0.1 \\
important & Very & 0.2 \\
& Strongly & 0.3 \\
& Moderately & 0.4 \\
& Equally & 0.5 \\
The subject is more & & \\
important & Moderately & 0.6 \\
& Strongly & 0.7 \\
& Very & 0.8 \\
& Highly & 0.9 \\
\hline
\end{tabular}

Table 2

Summary of 33 Year-Six Exam Scores

\begin{tabular}{lccccc}
\hline Description & $\begin{array}{c}\text { Mathematics } \\
(\mathrm{M})\end{array}$ & $\begin{array}{c}\text { Science } \\
(\mathrm{S})\end{array}$ & $\begin{array}{c}\text { Malay Language } \\
\text { Comprehension } \\
(\mathrm{MC})\end{array}$ & $\begin{array}{c}\text { Malay } \\
\text { Language } \\
\text { Written(MW) }\end{array}$ & $\begin{array}{c}\text { English } \\
(\mathrm{E})\end{array}$ \\
\hline Maximum & 69.0 & 68.0 & 88.0 & 85.0 & 80.0 \\
Minimum & 23.0 & 28.0 & 48.0 & 46.0 & 40.0 \\
Mean & 51.2 & 50.4 & 69.8 & 68.5 & 69.4 \\
Median & 51.0 & 50.0 & 68.0 & 70.0 & 70.0 \\
Standard deviation & 10.4 & 9.5 & 9.4 & 11.2 & 7.4 \\
\hline
\end{tabular}

In Table 2, the maximum scores for mathematics and science are lower than the maximum scores for the three language subjects, and lowest scores for mathematics and science are lower than the lowest score for language subjects. Furthermore, mean scores for mathematics and science are also lower than mean scores for Malay comprehension, written Malay and English. These data, show that students performed better in language subjects as compared to mathematics and science. The judgment of the relative importance of the five subjects by the five experts is summarized as in Table 3. 
Table 3

Judgment of The Relative Importance of Five Subjects by Five Experts

\begin{tabular}{lccccc}
\hline \multirow{2}{*}{ Subjects } & \multicolumn{5}{c}{ Experts } \\
\cline { 2 - 6 } & T1 & T2 & T3 & T4 & T5 \\
\hline Mathematics (M) & 0.50 & 0.50 & 0.50 & 0.60 & 0.50 \\
Science (S) & 0.50 & 0.50 & 0.60 & 0.60 & 0.50 \\
Malay Language Comprehension (MC) & 0.30 & 0.40 & 0.50 & 0.30 & 0.30 \\
Malay Language Written (MW) & 0.30 & 0.30 & 0.40 & 0.40 & 0.40 \\
English Language (E) & 0.30 & 0.30 & 0.40 & 0.30 & 0.40 \\
\hline
\end{tabular}

As shown in Table 3, teacher 1 evaluated mathematics and science as having about the same relatively higher importance than the other three subjects. The same trend is also found in the other four judgments. All teachers seemed to judge mathematics and science subjects as more important than the three language subjects. As only one set of weights or relative importance of the subject is needed in the SWA method, the values in every column were averaged. Table 4 illustrates the results.

Table 4

The Average Weight of Importance of the Five Subjects

\begin{tabular}{cc}
\hline Subjects & Weights \\
M & 0.52 \\
S & 0.54 \\
MC & 0.36 \\
MW & 0.36 \\
E & 0.34 \\
\hline
\end{tabular}

Table 4 shows that science received the highest score; mathematics is at the second highest position, only 0.2 lower than science. This might be due to their observation on how their pupils studied and struggled to have good grades for these two subjects. Besides that, it is well known that science subjects are more difficult to master as compared to other subjects. Subjects related to the Malay language (comprehension and writing) shared the third ranking, and English subject is ranked last. With the relative importance of the five 
subjects, the final scores of the students can be determined by SWA method by equation (4). Table 5 shows the SA scores, SA rankings, SWA scores and SWA rankings for the 33 students.

\section{Table 5}

SA scores, SA rankings, SWA scores and SWA rankings for 33 yearsix students

\begin{tabular}{|c|c|c|c|c|c|}
\hline No & Student & SA score & SA rankings & SWA scores & SWA rankings \\
\hline 1 & Student 31 & 72.4 & 1 & 71.18 & 1 \\
\hline 2 & Student 13 & 70.2 & 2 & 67.02 & 4 \\
\hline 3 & Student 5 & 69.4 & 3 & 69.10 & 2 \\
\hline 4 & Student 11 & 68.6 & 4 & 64.96 & 7 \\
\hline 5 & Student 27 & 67.4 & 5 & 68.05 & 3 \\
\hline 6 & Student 3 & 67.0 & 6 & 62.53 & 14 \\
\hline 7 & Student 32 & 67.0 & 6 & 64.72 & 8 \\
\hline 8 & Student 2 & 66.0 & 8 & 63.29 & 13 \\
\hline 9 & Student 20 & 66.0 & 8 & 66.07 & 5 \\
\hline 10 & Student 12 & 65.8 & 10 & 65.96 & 6 \\
\hline 11 & Student 28 & 65.6 & 11 & 64.52 & 9 \\
\hline 12 & Student 4 & 65.4 & 12 & 61.07 & 16 \\
\hline 13 & Student 29 & 65.0 & 13 & 63.47 & 11 \\
\hline 14 & Student 33 & 64.0 & 14 & 64.07 & 10 \\
\hline 15 & Student 30 & 63.2 & 15 & 60.89 & 17 \\
\hline 16 & Student 19 & 63.0 & 16 & 56.11 & 24 \\
\hline 17 & Student 26 & 62.8 & 17 & 59.91 & 19 \\
\hline 18 & Student 1 & 62.4 & 18 & 59.94 & 18 \\
\hline 19 & Student 21 & 62.2 & 19 & 58.99 & 21 \\
\hline 20 & Student 15 & 61.4 & 20 & 56.85 & 22 \\
\hline 21 & Student 16 & 60.2 & 21 & 63.37 & 12 \\
\hline 22 & Student 17 & 60.0 & 22 & 61.72 & 15 \\
\hline 23 & Student 24 & 60.0 & 22 & 59.57 & 20 \\
\hline 24 & Student 10 & 58.2 & 24 & 53.51 & 29 \\
\hline 25 & Student 18 & 57.6 & 25 & 55.03 & 25 \\
\hline 26 & Student 23 & 56.2 & 26 & 56.84 & 23 \\
\hline 27 & Student 6 & 55.8 & 27 & 54.69 & 27 \\
\hline 28 & Student 8 & 55.6 & 28 & 51.17 & 31 \\
\hline 29 & Student 25 & 55.6 & 28 & 54.80 & 26 \\
\hline 30 & Student 9 & 54.0 & 30 & 53.57 & 28 \\
\hline 31 & Student 22 & 53.8 & 31 & 52.90 & 30 \\
\hline 32 & Student 14 & 50.0 & 32 & 47.28 & 33 \\
\hline 33 & Student 7 & 49.6 & 33 & 47.31 & 32 \\
\hline
\end{tabular}


Table 5 demonstrates that there are differences in the overall scores and rankings of the students when different methods were used in finding overall aggregated values. The two methods gave different rankings on the students, except for the top position, position 18, position 25 , position 27 , and position 30 , but with different final score values. With regards to the first position, the results indicate that this pupil is good in all subjects, even though different weights are assigned to the subjects, but most of the other pupils were affected when the SWA was used as the aggregation method. Another interesting observation is that the use of SA gives the same scores for example to students $17,24,8$ and 25 , but there are no equal scores from SWA results.

Table 6 shows that, in terms of the overall scores, the SA method produces higher values in all categories, except the standard deviation value, as compared to SWA final scores. The lower standard deviation value in the SA results means that the scores deviated less from the mean as compared to the distribution of the SWA scores.

Table 6

Summary of SA and SWA Final Scores

\begin{tabular}{lcc}
\hline Description & SA & SWA \\
Maximum & 72.4 & 71.2 \\
Minimum & 49.6 & 47.3 \\
Mean & 61.9 & 60.0 \\
Median & 62.8 & 60.9 \\
Standard deviation & 5.8 & 6.1 \\
\hline
\end{tabular}

\section{CONCLUSION}

From the point of view of teachers, administrators and policy makers it is desirable to be able to obtain one single overall score of each analyzed unit where a certain aggregation or composition method is used. This paper suggests Simple Weighted Average (SWA) method as an alternative method to simple averages in finding the final single scores. In this small scale case study, the relative importance of five core primary school subjects was determined by five teachers from the same school. They viewed mathematics and science subjects to be more important as compared to language subjects. When these weights of importance of the subjects were later used in aggregating 
the scores of 33 students of year-six, the final scores were different from the set of final scores obtained by Simple Average (SA) method, but the top position was not affected. Moreover, same final scores can be avoided if SWA is used instead of SA

Even though the results of this study cannot be generalized, but the case study carries one important implication. SWA is an alternative method to be used in composing students' academic achievement in different subjects because the academic subjects were treated to have different relative importance which is what takes place in the educational context. It is suggested that teachers or the authorities in the department at education in any level of educational institutions should review and reconsider the issue of different relative importance of different academic subjects since it has some implication on the pupils' overall academic achievement. However, the relative importance of the subjects is undeniably subjective. This is due to the method used in finding the degree of importance, as well as the different background of the evaluators. Besides that, the interdependencies or interactions between the subjects created another important issue and worthwhile to be investigated in future research.

\section{ACKNOWLEDGEMENT}

This research is funded by Ministry of Higher Education of Malaysia under Fundamental Research Grant Scheme (FRGS) with S/O Code:11877, 2009-2012.

\section{REFERENCES}

Barron, F. H., \& Barrett, B. E. (1996). Decision quality using ranked attribute weights. Management Science, 42 (11), 1515-1523.

Choo E.U, Schooner B., \& Wedley W.C. (1999). Interpreting of criteria weights in multi criteria decision making. Computers \& Industrial Engineering, 37, 537-541.

Diakoulaki D, Mavrotas G, \& Papayannakis L. (1995). Determining objective weights in multiple criteria problems: the CRITIC method. Computers and Operation Research, 22 (7), 763 - 770.

Hazura, Z., Abdul Azim, A., G., Mohd Hasan, S., \& Ramlan, M. (2007). Using fuzzy integral to evaluate the web-based 
applications. Paper presented at the proceedings of the Fifth International Conference on Information Technology in Asia, 23-27.

Hwang, C.L., \& Yoon, K. (1981). Multiple attribute decision making: Methods and applications. New York: Springer-Verlag.

Kane M., \& Case S. (2004). The reliability and validity of weighted composite scores. Applied Measurement in Education, 17(3), 221-240.

Kolen M. J., Wang T., \& Lee, W. (2012) Conditional standard errors of measurement for composite scores using IRT. International Journal of Testing, 12,1 - 20.

Ma, J., Fan, Z. P., \& Huang, L.H. (1999). A subjective and objective integrated approach to determine attributes weights. European Journal of Operational Research, 112, 397-404.

Marichal, J. L. (1999). Aggregation operator for multi-criteria decision aid (Unpublished doctoral dissertations). University of Liege.

Maznah Mat Kasim (2008). Determination of criteria weights in multi criteria problem (in Malay).( Unpublished doctoral dissertations). Universiti Kebangsaan Malaysia (UKM), Malaysia.

Mohd Faisal Imran. (2007). Student's Educational Information Mangement System Case Study: Sekolah Kebangsaan Serkam Darat. Degree project paper, Technical University of Malaysia.

Muhamad Ayub. (2009). Choquet and Sugeno Integrals(Unpublished master's thesis). Blekinge Institute of Technology.

Saaty, T. L. (1990). How to make a decision: the Analytic Hierarchy Process. European Journal of Operational Research, 48(1), 9-26.

Tan C., \& Chen X. (2010). Intuitionistic fuzzy choquet integral operator for multi-criteria decision making. Expert Systems with Applications, 37(1), 149-157.

Wagholikar, A. S., \& Deer, P. (2007). Fuzzy measures acquisition methods. Engineering Letters (IAENG), 14(2), 56-60.

Wagholikar, A. S. (2007). An approach to improve practical application of fuzzy measures in multi-criteria decision making. Paper presented at the proceedings of NAFIPS International Conference 2007, 222-226.

Wagholikar, A. S., \& Jo, J. (2008). An intelligent system in healthcare using fuzzy measures. Paper presented at the Proceedings of $20083^{\text {rd }}$ International Conference on Intelligent System and Knowledge Engineering, 446-449. 
Wei Y.L, \& Hsiao S. (2012). Parents value language, math over nature science: Poll in Focus Taiwan News Channel 2012/06/29. http://focustaiwan.tw/ShowNews/WebNews_Detail. aspx $?$ Type $=$ aALL \&ID $=201206290042$

Yao L. (2010). Reporting valid and reliable overall scores and domain scores. Journal of Educational Measurement, 47(3), 339-360. 